\title{
Trehalose 6,6'-Dimycolate and Lipid in the Pathogenesis of Caseating Granulomas of Tuberculosis in Mice
}

Robert L. Hunter, Margaret Olsen, Chinnaswamy Jagannath, and Jeffrey K. Actor

From the Department of Pathology and Laboratory Medicine, University of Texas-Houston Medical School, Houston, Texas

Trehalose 6,6'-dimycolate (TDM) is the most abundant, most granulomagenic, and most toxic lipid extractable from the surface of virulent Mycobacterium tuberculosis (MTB). We further examined its toxicity, which requires activation by oily surfaces. Injections of MTB and/or TDM into sensitized mice induced caseating granulomas that centered on oil droplets. If large doses of MTB were injected in saline, caseating granulomas developed in adipose tissue, but MTB with surface TDM removed induced only acute inflammation that did not persist. Variations in protocols produced several variants of caseating granulomas, each with characteristics of human tuberculosis. In each instance, MTB were localized in fat cells or oil drops during initiation of caseating granulomas suggesting that necrosis was caused by activation of the toxicity of TDM toxicity. Evidence extending these findings to the lung was derived from the observation that in sensitized mice, as in humans, tuberculosis development stimulates accumulation of lipid selectively in alveoli. MTB preferentially associated with lipid droplets in developing necrotic foci in late-stage murine tuberculosis. This supports the hypothesis that pulmonary tuberculosis sequesters MTB in a protected environment that accumulates lipid until it is able to activate the toxicity of TDM and initiate necrosis that results in caseating granulomas. (Am J Pathol 2006, 168:1249-1261; DOI: 10.2353/ajpath.2006.050848)

The cell wall of Mycobacterium tuberculosis (MTB) contains many lipids. ${ }^{\prime}$ Among these, trehalose 6,6' dimycolate (TDM) or cord factor has unique properties. It is the most toxic, most granulomagenic, and most abundant lipid extractable from the surface of MTB. ${ }^{2}$ Recent data suggest that it is responsible for the characteristic colony morphology of virulent organisms. ${ }^{3}$ TDM is a highly water-insoluble wax-like substance that is a potent immunoadjuvant for enhancing cell-mediated immune responses. ${ }^{4,5}$ TDM induces activated foreign body-type granulomas in naïve mice or hypersensitivity (immune) granulomas in appropriately sensitized mice. ${ }^{6-9}$

The most unusual characteristic of TDM is that its biological activities change dramatically in different environments. TDM on the surface of MTB inhibits phagosome-lysosome fusion and protects organisms from killing within macrophages in vitro and promotes their survival in vivo. ${ }^{10,11}$ TDM spread as a molecular monolayer on hydrophobic interfaces becomes orders of magnitude more toxic than any other mycobacterial lipid. ${ }^{12-14}$ Susceptible mice can be killed by as little as $30 \mu \mathrm{g}$ of TDM administered as an oil-in-water emulsion in divided doses, but suffer no toxic effects from 1000-fold higher doses without oil. ${ }^{5,15}$ In vitro, oil emulsions of TDM induce proinflammatory cytokines and are toxic for macrophages. ${ }^{16,17}$ The requirement for oil was explained by the demonstration that TDM can assume either a mycellar configuration that is nontoxic or a monolayer configuration that is highly toxic. ${ }^{13}$ Its toxicity is a direct function of the surface area of a crystalline monolayer that forms at hydrophobe-aqueous interfaces. ${ }^{14,18,19}$

The fact that TDM is the most abundant lipid free on the surface of virulent MTB and has the ability to switch between sets of biological activities depending on its physical conformation suggests that it may contribute to the pathogenesis of tuberculosis in different ways at different stages of infection. Bloch and Noll ${ }^{15}$ reported that injections of TDM in oil enhanced both acute and chronic tuberculosis in mice. These reports stimulated enduring controversy because TDM was found in nonpathogenic mycobacteria and the requirement for oil was considered "unphysiologic." ${ }^{20}$ Nevertheless, the studies of the effects of TDM on infection have never been repeated. In

\footnotetext{
Supported by the United States Public Health Service (grant HL 68537) Accepted for publication January 4, 2006.

Address reprint requests to Robert L. Hunter M.D., Ph.D., Department of Pathology and Laboratory Medicine, MSB 2.136, 6431 Fannin, Houston, TX 77030. E-mail: robert.I.hunter@uth.tmc.edu.
} 
repeating these studies, we found that intraperitoneal injection of sensitized mice with an oil-in-water emulsion of TDM induced caseating granulomas in adipose tissue of the peritoneal cavity.

Caseating granulomas are the characteristic lesion of active tuberculosis in humans, but have seldom been reported in mice. ${ }^{21,22}$ Consequently, studies were designed to characterize the murine caseating granulomas, learn the conditions under which they form, and investigate how they might be relevant to the human disease. Because we knew that mice are capable of producing caseating granulomas, but do not do so after the usual low-dose aerosol or intravenous infection, a different approach was needed. Studies were designed based on reports that caseating granulomas in the adult human lung frequently develop abruptly from necrosis of tuberculous pneumonia in which very large numbers of MTB are present within the alveoli of individuals with a high degree of hypersensitivity. ${ }^{23-26}$ In an attempt to reproduce these conditions, sensitized mice were injected in the peritoneal cavity or lung with very large doses of MTB. Mice so injected did produce tuberculous pneumonia or peritonitis, but the lesions quickly and completely resolved unless the organisms became localized in adipose tissue or droplets of oil where they formed caseating granulomas. Multiple variants of caseating granulomas were produced each of which replicated characteristics of human disease.

The localization of caseating granulomas in adipose tissue is characteristic of human mesenteric tuberculosis, but not of the more important pulmonary disease. ${ }^{27,28} \mathrm{~A}$ search for a possible source of lipid in the lung revealed that slowly progressive pulmonary tuberculosis in the mouse is a pneumonic process similar to that thought to precede the development of pulmonary caseating granulomas in adult humans. ${ }^{23-25,29}$ Lipids progressively accumulate in both human and murine pulmonary lesions before the development of necrosis. ${ }^{23,29-31}$ Our final study demonstrated MTB preferentially associated with lipid droplets of lesions of chronic murine tuberculosis when they were beginning to undergo necrosis. These data support the hypothesis that pulmonary tuberculosis sequesters MTB in a protected environment that progressively accumulates lipid that eventually gains the mass and physical characteristics necessary to activate the toxicity of TDM and initiate necrosis that results in caseating granulomas.

\section{Materials and Methods}

MTB Erdman (ATCC no. 35801) was obtained from The American Type Culture Collection (Rockville, MD) and cultured to log phase in Middlebrook $7 \mathrm{H} 9$ broth. Bacteria were pelleted, washed, suspended in saline, gently sonicated to disperse clumps, and matched in turbidity to McFarland no. $1\left(3 \times 10^{8} \mathrm{CFU} / \mathrm{ml}\right)$. They were frozen in aliquots at $-70^{\circ} \mathrm{C}$. TDM from MTB (Sigma Chemical Co., St Louis, MO) was formulated as a $2 \%$ mineral oil-in-water emulsion as described. ${ }^{18}$ Lipids were extracted from the surface of viable MTB Erdman by a modification of the procedure of Bloch to produce delipidated MTB. ${ }^{11,32}$ The predominance of TDM in the extracted lipid was confirmed by thin layer chromatography. ${ }^{11}$ Peritoneal tuberculosis was induced in groups of 20 7-to 9-week-old C57BL/6 mice (Jackson Laboratories, Bar Harbor, ME) by intraperitoneal injection of $10^{9}$ or $10^{7}$ MTB in saline or in a $2 \%$ squalane-in-water emulsion according to the method of Pierce. ${ }^{33}$ For study of acute tuberculosis, C57BL/6 mice 10 weeks old (Jackson Laboratories) were injected intraperitoneally in groups of 30 with $100 \mu \mathrm{g}$ of TDM in $0.5 \mathrm{ml}$ of emulsion 24 hours before intravenous infection with $10^{6} \mathrm{MTB}$. The animals were killed in groups of four to five at intervals for CFU determinations on $7 \mathrm{H} 11$ agar and histopathology of the lung, liver, and spleen by standard procedures. ${ }^{34}$

For study of the effects of TDM on tuberculosis in sensitized animals, mice were infected with a low dose of MTB ( $10^{4}$ CFUs) to produce an infection that would remain static at a low level for 12 to 24 months. ${ }^{29}$ Such mice produce well developed T-cell and hypersensitivity reactions to mycobacterial antigens. Other mice were sensitized by an intraperitoneal injection of $100 \mu \mathrm{g}$ of TDM in an oil-in-water emulsion. C57BL/6 or BALB/C (Jackson Laboratories) 5- to 7-week-old mice were injected intravenously in groups of 20 to 30 with $10^{4}$ MTB. MTB stock suspension in saline was diluted to contain $10^{4} \mathrm{CFU} / 0.2$ $\mathrm{ml}$, which was injected through the lateral tail vein. Minimal or no acid-fast bacilli (AFB) or histopathological lesions were seen in any of these animals at 30,56 , or 90 days. The CFU counts of both TDM-injected and control mice remained below the limit of detection (1000 CFU/ organ). Groups of 15 to 20 mice were injected intraperitoneally with $100 \mu \mathrm{g}$ of TDM in $0.2 \mathrm{ml}$ of an oil-in-water emulsion or with $10^{9}$ or $10^{7}$ MTB in the lung or peritoneal cavity on days 30 to 40 after the immunizing infection. Injections into the lung were through the rib cage on the right side taking care to deposit the material in the lung tissue where most entered alveoli. In each experiment, animals were killed in groups of four to five for examination of tissues at intervals after challenge. Tissues were fixed in $10 \%$ neutral buffered formalin and examined with a dissecting microscope to identify lesions for sectioning. The tissues were trimmed to display the lesions, embedded in paraffin, sectioned, and stained with hematoxylin and eosin (H\&E) or AFB by routine procedures.

\section{Results}

\section{Induction of Peritoneal Caseating Granulomas by TDM in Sensitized Mice}

Stimulated by reports that intravenous injection of TDM emulsions into specifically sensitized mice induces hypersensitivity granulomas, we undertook to study the role of such granulomas in tuberculosis. ${ }^{7,9,35}$ Mice sensitized by low-dose infection with MTB were injected intraperitoneally with TDM as an oil-in-water emulsion and examined at 3 weeks. This produced dense lymphocytic infiltration of mesenteric and omental fat and caseating granulomas. Some lesions had extensive lymphocytic 

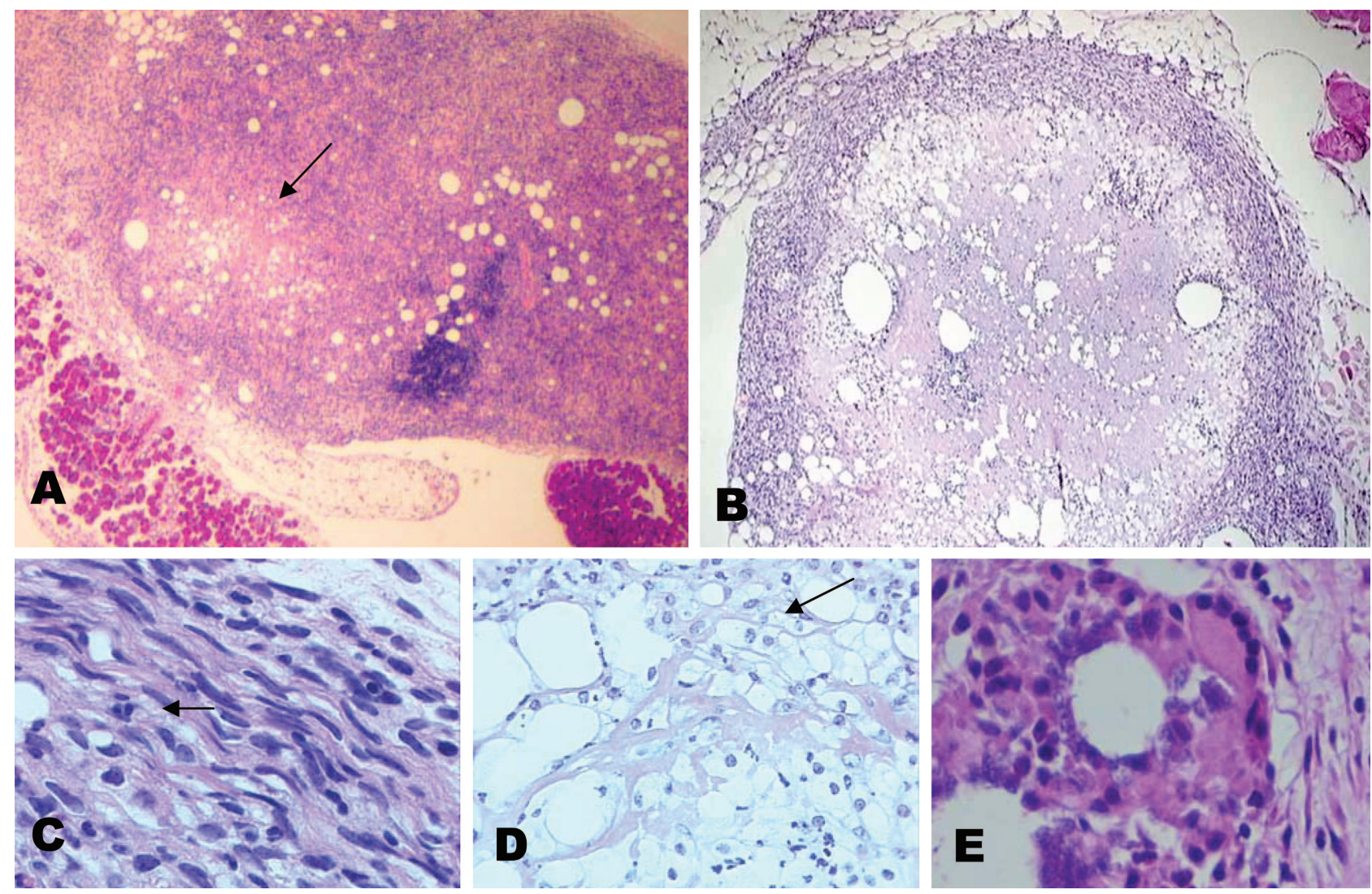

Figure 1. Caseating granuloma induced by TDM in a sensitized mouse. Animals were injected intraperitoneally with $100 \mu \mathrm{g}$ of TDM as a $2 \%$ oil-in-water emulsion 30 days after immunization with $10^{4}$ MTB. A: Section of a lesion 21 days after injection of TDM showing dense lymphoid cell infiltration of mesenteric fat containing a smaller area of foamy and degenerating macrophages suggesting early caseous change (arrow) (H\&E). B: Section of a lesion 21 days after injection of TDM showing a larger caseating granuloma composed of epithelioid macrophages surrounding a central core of amorphous necrotic material. Many of the holes are remnants of fat cells (H\&E). C: Detail of $\mathbf{B}$ showing epithelioid cells and fibroblasts. Many lymphocytes were located outside the layer of epithelioid cells (H\&E). D: Detail of $\mathbf{A}$ at arrow showing fat cells infiltrated and apparently being degraded by foamy macrophages (H\&E). E: Section of a lesion 80 days after injection of TDM showing multinucleated macrophages resembling Langhans giant cells (H\&E). Original magnifications: $\times 20(\mathbf{A}, \mathbf{B}) ; \times 400(\mathbf{C}, \mathbf{E}) ; \times 500(\mathbf{D})$.

infiltration with small areas of necrosis whereas others had much larger areas of typical caseous necrosis (Figure 1, A and B). The outermost layer of the granulomas consisted of lymphocytes, macrophages, eosinophils, fibroblasts, and small blood vessels. Progressing inward, macrophages assumed the appearance of epithelioid cells with elongated to oval nuclei surrounded by fairly abundant, faintly granular, pink cytoplasm with poorly defined cell margins (Figure 1C). A layer of degenerating epithelioid cells with dark pink hylanized cytoplasm and pyknotic nuclei was seen just beneath the epithelioid cells in some places. In other areas, the epithelioid cells gave way to foamy macrophages. The interior of the lesions were avascular and composed of cell ghosts and amorphous debris.

These granulomas eroded from adipose tissue into liver, pancreas, and muscle. In liver and muscle, remnants of parenchymal tissue were seen only at the periphery and were degenerating suggesting that they were being destroyed by the advancing granuloma. Fat tissue was different. Recognizable fat cells were seen deep in the granulomas. Early signs of caseation necrosis were associated with macrophages and fragmented fat cells that appeared to merge into the lipid of caseation necrosis (Figure 1D). The lesions slowly regressed after 1 month. Giant cells with intensely staining pink cytoplasm and multiple peripherally located nuclei characteristic of Langhans cells appeared at 2 to 3 months (Figure 1E). ${ }^{26}$

Several control experiments were conducted to investigate the immunological parameters of these lesions. First, the oil vehicle by itself was not granulomagenic. It induced only mild foreign body reactions. Next, injection of the TDM emulsion into nonimmune control mice induced nonimmune granulomas composed of macrophages with few lymphoid cells and little or no necrosis as has been frequently reported. 6,9,35,36 Finally, we confirmed the observation of Bekierkunst and Yarkoni ${ }^{7}$ that oil emulsions of TDM are not able to immunize mice for production of hypersensitivity granulomas after challenge with TDM. Such immunization has been accomplished only by infection with mycobacteria or injection of TDM complexed to methylated bovine serum albumin. ${ }^{7,35}$

\section{Induction of Caseating Granulomas by MTB}

Studies were undertaken to determine whether virulent MTB that contain TDM could induce caseating granulomas. Large doses of MTB were chosen in an effort to reproduce the conditions reported to exist in the adult 

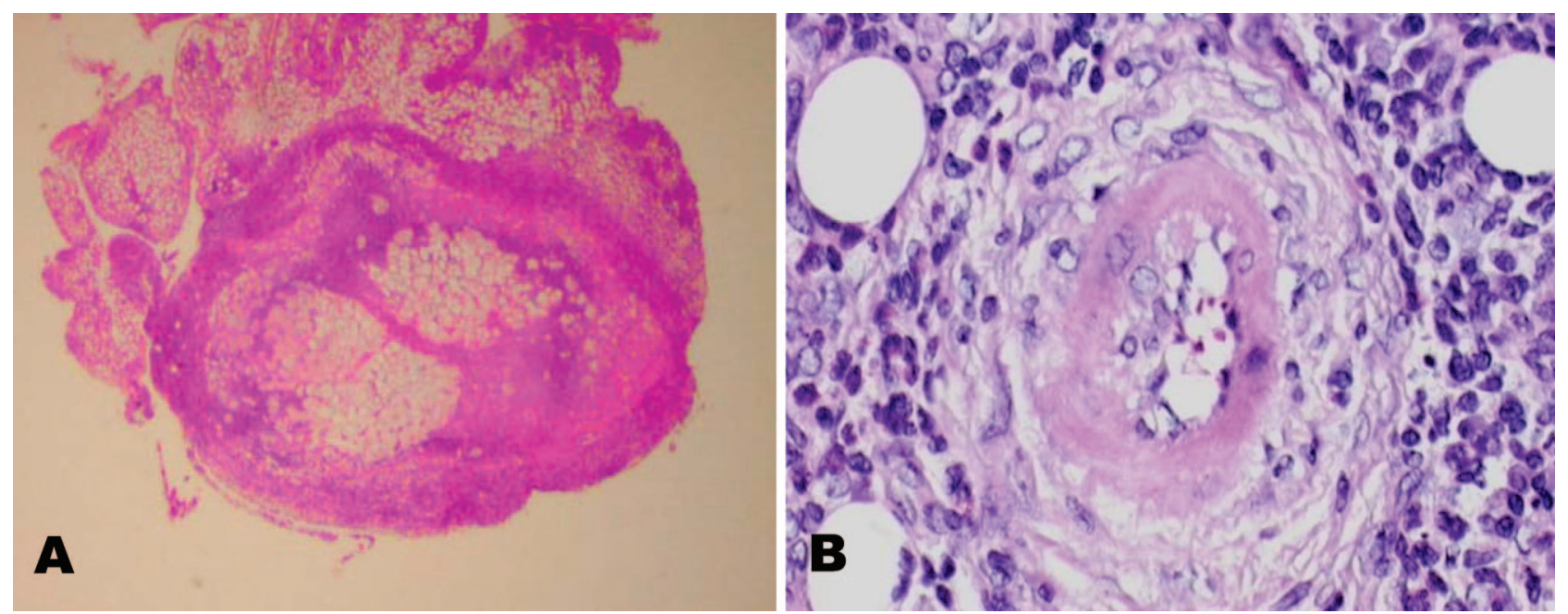

Figure 2. Granulomas induced by MTB in peritoneal cavities of sensitized mice. The animal was injected intraperitoneally with $10^{9}$ MTB 30 days after immunization with $10^{4}$ MTB intraperitoneally and examined on day 28 . A: Lesion containing multiple foci of intense infection and infarcted tissue surrounded by a fibrin-fibrous capsule (H\&E). B: Detail of blood vessels immediately outside of lesion showing lymphocyte cuffing, medial, and endothelial damage (H\&E). Original magnifications: $\times 20(\mathbf{A}) ; \times 400(\mathbf{B})$.

human lung immediately preceding development of caseating granulomas and to contain an adequate dose of TDM. ${ }^{24,25}$ We found that intraperitoneal injection of $10^{9}$ MTB in saline or oil into sensitized mice induced caseating granulomas in all mice. Animals injected with a smaller number of organisms $\left(10^{7}\right)$ had no caseating granulomas and little other histological evidence of infection throughout the time course (data not shown). The lesions produced by the high dose were similar to those induced by TDM in that they developed in adipose tissue, consisted of lymphoid and epithelioid cells and fibrin surrounding necrotic tissue (Figure 2A). They differed in that the central necrosis was larger and more distinctly separated from the viable epithelioid cells. In addition, they contained large numbers of AFB. Lymphocytes and other inflammatory cells were prominent immediately outside of the layer of epithelioid cells. These lesions per- sisted through the end of the experiment, 60 days. AFB remained prominent in the lesions even though their numbers declined throughout time. Much smaller numbers of AFB were present in the spleen and liver, but not in the lung during the course of the experiments.

The lesions in these animals frequently demonstrated evidence of a second type of necrosis characterized by infarcted tissue surrounded by a rim of macrophages and fibrin. These lesions contained variable numbers of distinct foci of infection separated by infarcted uninfected tissue. The entire lesion was surrounded and clearly delimited by a layer of epithelioid macrophages and fibrin. The small blood vessels on the periphery of the lesions were cuffed with Iymphocytes, contained inflammatory cells within the endothelium, and showed swelling and degeneration of endothelial cells (Figure 2B). These tissue and vascular
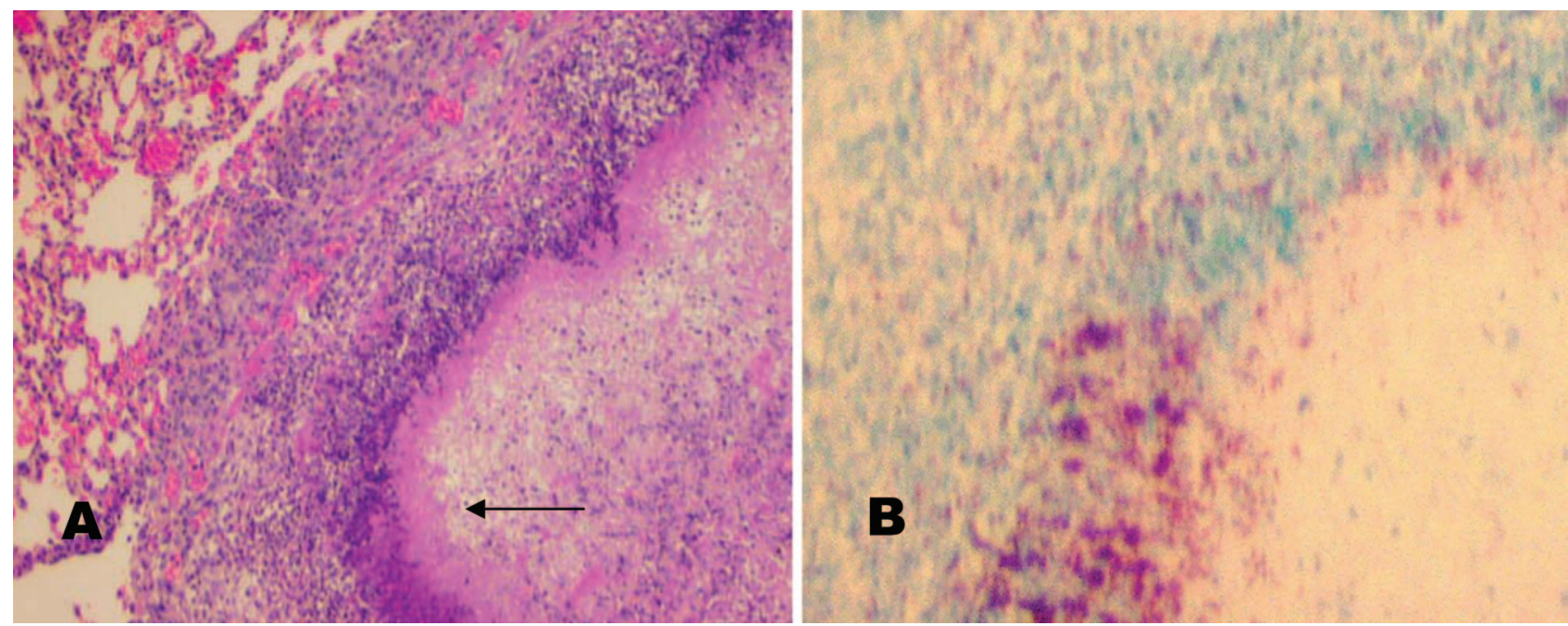

Figure 3. Caseation granuloma in lung after intraperitoneal injection. The animal was injected intraperitoneally with $10^{9} \mathrm{MTB} 30$ days after immunization with $10^{4}$ MTB intraperitoneally and sacrificed on day 7. A: Photomicrograph of a caseating granuloma in the mediastinum invading the lung (H\&E). B: Acid fast stain of same lesion showing masses of organisms near arrow on A. These were the only AFB found above the diaphragm (AFB). Original magnifications: $\times 20$ (A); $\times 30(\mathbf{B})$. 

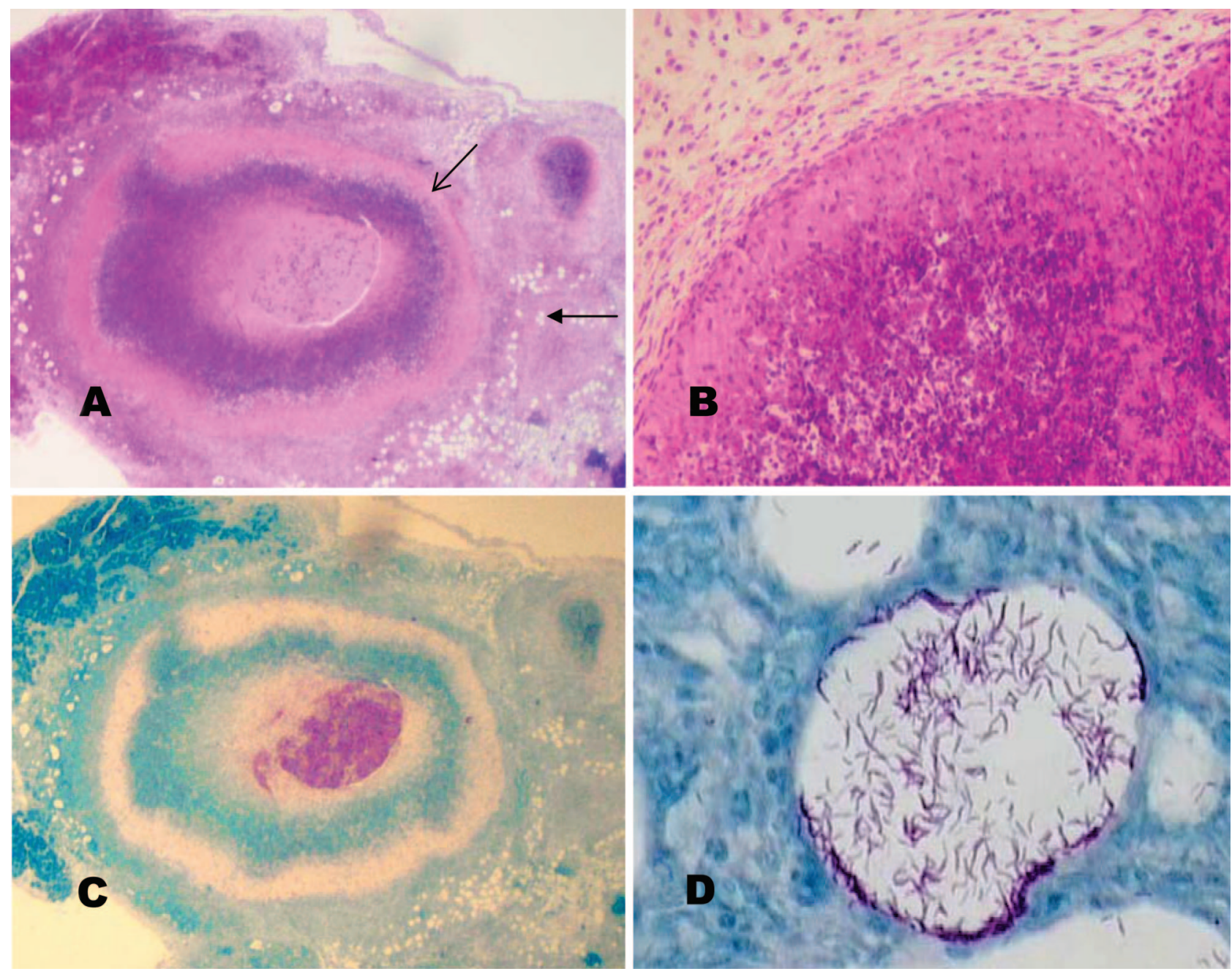

Figure 4. Caseating granulomas in nonsensitized mice. The animal was injected intraperitoneally with $10^{9} \mathrm{MTB}$ and examined 14 days later. Arrows mark areas shown on $\mathbf{B}$ and $\mathbf{D}$. A: Section of a necrotic lesion in adipose tissue adjacent to the pancreas. A separate smaller lesion is present on the top right (H\&E). B: Detail of lesion showing epithelioid cells with very few lymphocytes surrounding necrotic material (open arrow on A) (H\&E). C: Masses of MTB contained within the lesion (AFB stain). D: Detail showing MTB in fat cells in periphery of lesion (closed arrow on A) (AFB stain). Original magnifications: $\times 20$ (A, C); $\times 200(\mathbf{B})$; $\times 400$ (D).

changes are characteristic of delayed type hypersensitivity reactions. ${ }^{37}$

Most of the caseating granulomas were located near the site of injection in the peritoneal cavity. However, some were found at a distance in the mediastinum where they had eroded into lung tissue (Figure 3A). These lesions were located on the path of lymphatic drainage from the peritoneal cavity and contained large numbers of AFB (Figure 3B). Interestingly, no AFB were found in the surrounding connective tissue, lymph nodes, lung, or any other site in the chest. These lesions are consistent with the reports that caseating granulomas serve to sequester MTB and retard further spread of infection. ${ }^{38}$

\section{Induction of Nonimmune Caseating Granulomas in Naive Mice}

Studies were conducted with normal mice to evaluate the role of immunization in induction of caseating granulomas. Mice were injected intraperitoneally with $10^{9} \mathrm{MTB}$ in saline and sacrificed on days 7,14 , and 28 . Many more AFB persisted in the organs of these mice than in the sensitized mice that had been similarly challenged consistent with the ability of cell-mediated immunity to kill organisms and retard dissemination. Nevertheless, the animals showed no clinical evidence of illness during the course of the study. The tissues demonstrated histological evidence of early tuberculosis in the spleen, liver, and lung. The largest lesions, however, were caseating granulomas in peritoneal adipose tissue (Figure 4A). These lesions had characteristics of nonimmune granulomas. They had central necrosis surrounded by a ring of macrophages with epithelioid appearance and very few lymphocytes (Figure 4B). The necrotic centers consisted of an innermost zone of amorphous material with vast numbers of AFB (Figure 4C). An intermediate zone contained much nuclear debris. The outer zone consisted of densely eosinophilic material that appeared to be degenerating protein-rich cells. AFB were present throughout the necrotic tissue and in degenerating fat cells near the 

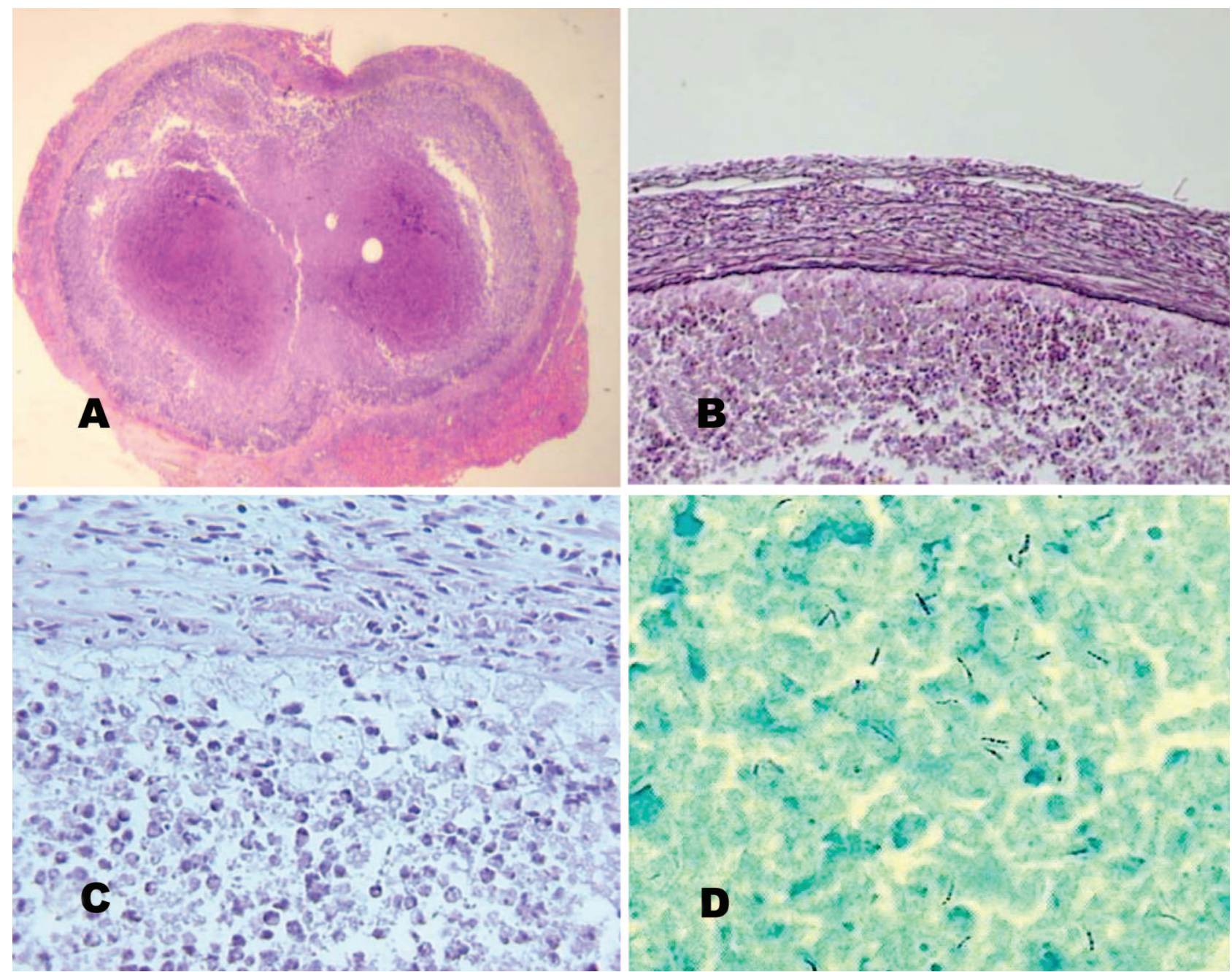

Figure 5. Persistent caseating granulomas induced by MTB plus TDM. The animal was injected intraperitoneally with $100 \mu \mathrm{g}$ of TDM in an oil-in-water emulsion and with $10^{6}$ MTB intravenously 1 day later. The lesions were examined 80 days later. A: Section of an encapsulated lesion consisting of dense connective tissue, fibroblasts, and macrophages surrounding caseation necrosis with focal calcification (H\&E stain). B: Connective tissue stain of lesion like A showing a continuous fibrous capsule associated with containment of organisms (reticulum stain). C: Detail of lesion A showing thin layer of foamy macrophages between the capsule and interior necrotic material. Only a few lymphocytes or epithelioid macrophages were present in the outer rim of the lesion (H\&E stain). D: Many more MTB were present in this lesion than in any other part of the body. They were evenly distributed in the necrotic tissue and were less acid fast than those observed in earlier lesions (AFB stain). Original magnifications: $\times 20(\mathbf{A}) ; \times 100(\mathbf{B}) ; \times 400(\mathbf{C}) ; \times 1000(\mathbf{D})$.

periphery of the lesions, but not in the surrounding layer of epithelioid cells. The AFB in fat droplets were dispersed as single organisms in a manner reminiscent of AFB in oil droplets (Figure 4D). ${ }^{32}$ They were consistently present at 7 days, but appeared to be consumed by advancing necrosis as the lesions aged. Injection of a lower dose $\left(10^{7}\right)$ of MTB produced much less infection of the liver and spleen and no caseating granulomas.

\section{Prolonged Sequestration of AFB in Caseating Granulomas}

A study undertaken to evaluate the effects of TDM on acute tuberculosis demonstrated an ability of caseating granulomas to sequester and protect organisms after the host had acquired sufficient immunity to clear organisms from the liver and spleen and restrict their growth in the lung. Mice were injected with TDM intraperitoneally 1 day before infection with a moderate dose $\left(10^{6}\right)$ of MTB intravenously to produce a subacute infection in which MTB increased for 30 days to a peak of $10^{6}$ CFUs in the lung before declining to a quiescent phase of chronic tuberculosis with $10^{5}$ CFUs in the lung at 80 days. ${ }^{39}$ TDM caused a $1 \mathrm{log}$ increase in organisms in the lung, at 30 days, but did not inhibit the clearing of organisms and resolution of the histopathological changes in the lung, liver, and spleen at 80 days. However, caseating granulomas with large numbers of AFB persisted in the peritoneal cavities of these mice (Figure 5A). These lesions consisted of a fibrous capsule surrounding an avascular area of foamy macrophages and caseous-appearing material. The fibrous capsules stained strongly for collagen and consisted primarily of fibroblasts and macrophages with few lymphocytes and no epithelioid cells (Figure 5B). Beneath the capsule, there was a sharp transition to a thin layer of foamy macrophages (Figure 5C). Beneath 


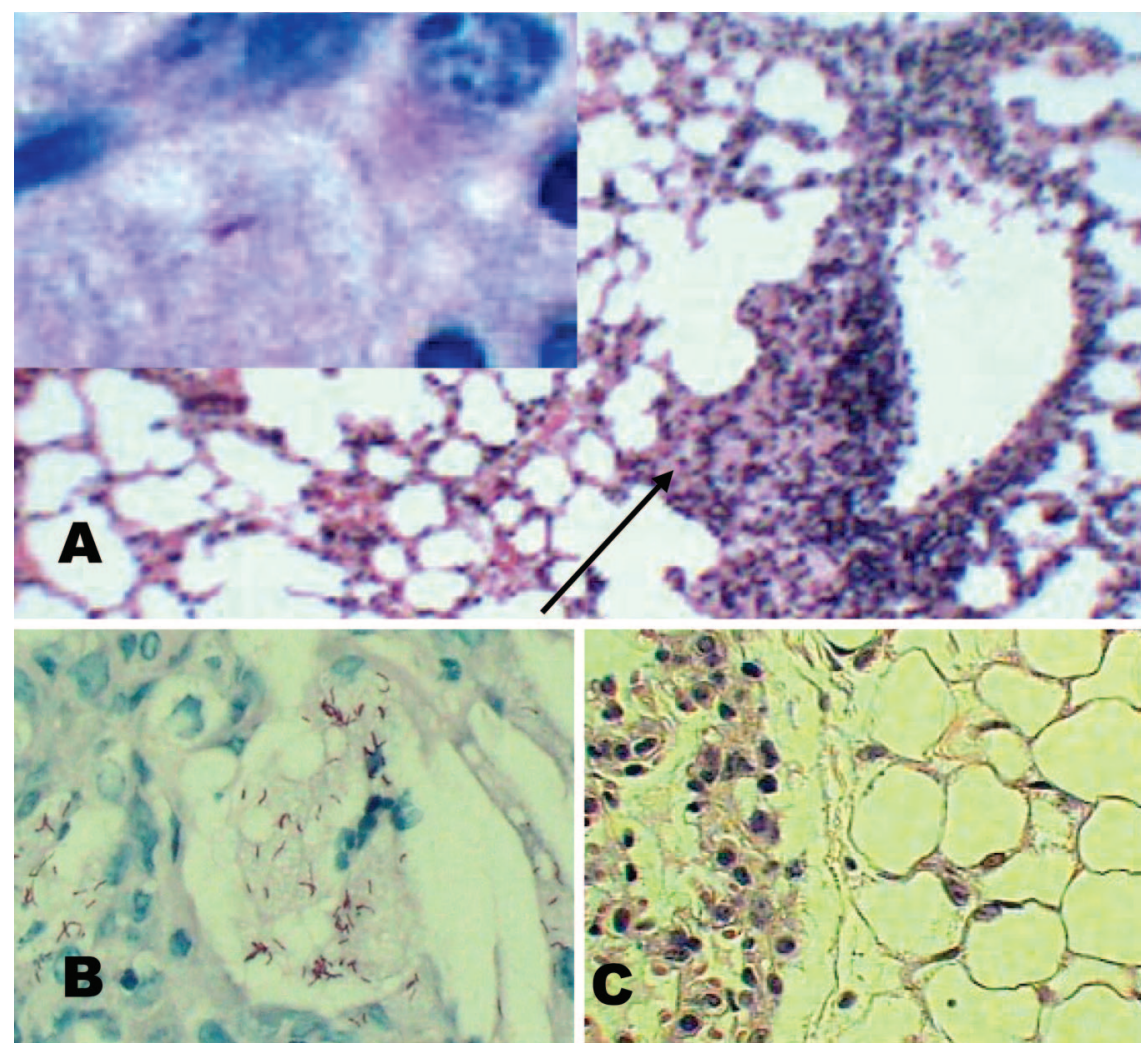

Figure 6. Histopathology of slowly progressive pulmonary tuberculosis. A: AFB in the lung of a mouse 2 months after infection with $10^{4}$ MTB i.p. $\mathrm{AFB}$ had been cleared from the liver and spleen by this time and small foci of infection had developed in the lung. A single AFB in a foamy alveolar macrophage (inset) was found in sections of the lungs of five mice (arrow). B: Association of AFB with lipid drops in late-stage slowly progressive murine tuberculosis. Section from lung of a mouse 300 days after intravenous infection with MTB strain H37Rv shows the characteristic accumulation of lipid, especially cholesterol crystals, in a focus of infection. Organisms are located within lipid drops in association with cholesterol crystals demonstrating that the association of MTB with lipid in the lung can be physiological (AFB stain). C: Adipose tissue in normal mouse lung. The lungs of mice typically contain small deposits of adipose tissue near the hilus. Caseating granulomas preferentially formed in such tissue (H\&E). Original magnifications: $\times 1000(\mathbf{B}) ; \times 200(\mathbf{C})$. the foamy macrophages, there were only degenerating or dead macrophages, cell ghosts, and mildly eosinophilic debris. The lesions calcified irregularly within the necrotic mass. The number of MTB in these lesions was assessed by counting the number of AFB/oil immersion field and multiplying by the volume of the lesion/volume of section examined. By this measure, there were in excess of $10^{8}$ MTB in each caseating granuloma suggesting that MTB survived in these lesions after most had been cleared from other organs (Figure 5D).

\section{Induction of Caseating Granulomas in the Lung}

Because an estimated $80 \%$ of all human tuberculosis occurs in the lung, studies were undertaken to determine whether similar procedures could induce pulmonary caseating granulomas. ${ }^{22,40}$ The approach was based on the above findings and reports that caseating granulomas in the human lung frequently develop within days from a pneumonic process. ${ }^{25}$ The tissues of mice sensitized for 2 months with a low-dose $\left(10^{4}\right)$ MTB intraperitoneally were examined to establish a baseline before attempting to induce pulmonary caseating granulomas. They showed several features of interest. First, AFB and histological evidence of infection that had been observed in the liver and spleen at 3 weeks after infection had been cleared. The lungs contained only small scattered foci of tuberculosis. Only one acid fast organism was found in sections of the lungs of five mice (Figure 6A). This organism was located in a foamy macrophage in an alveolus near a focus of interstitial lymphocyte infiltration. This is the typical lesion of early slowly progressive pulmonary tuberculosis that would progress and eventually kill the animal. ${ }^{29}$ At 300 days, these lesions had progressed. Many AFB were found within or closely associated with lipid drops and cholesterol crystals in or near necrotic foci (Figure 6B). These lesions demonstrate that natural tuberculosis in the mouse lung can induce accumulation of lipids with droplet size comparable to that of mineral oil and fat cells in our experiments. Finally, mouse lungs characteristically contain small numbers of fat cells near the hilus (Figure 6C).

Sensitized mice were injected into the right lung with the same high dose of MTB that induced caseating granulomas in the peritoneal cavity. This induced an acute pneumonitis and caseating granulomas, as expected, but surprisingly they were separate and distinct processes. The animals appeared normal on day 1 , slightly ill on day 2, and very ill on day 3 when some died of diffuse pulmonary inflammation and edema. After day 3, the surviving animals recovered and appeared clinically normal for the duration of the experiment. Histologically, the lungs of these animals demonstrated several remarkable features. First, the large dose of organisms was surprisingly well tolerated. There was no evidence of shock and organ failure such as produced by endotoxincontaining gram-negative bacteria or the abscesses produced by some gram-positive organisms. Large numbers of AFB were present in the lungs of these mice at 1 hour after injection (Figure 7E). Some organisms were observed in clumps along the needle track or near the site of injection, but many had become widely scattered through the alveoli and airways. The clumps were surrounded by debris of dead macrophages and neutro- 

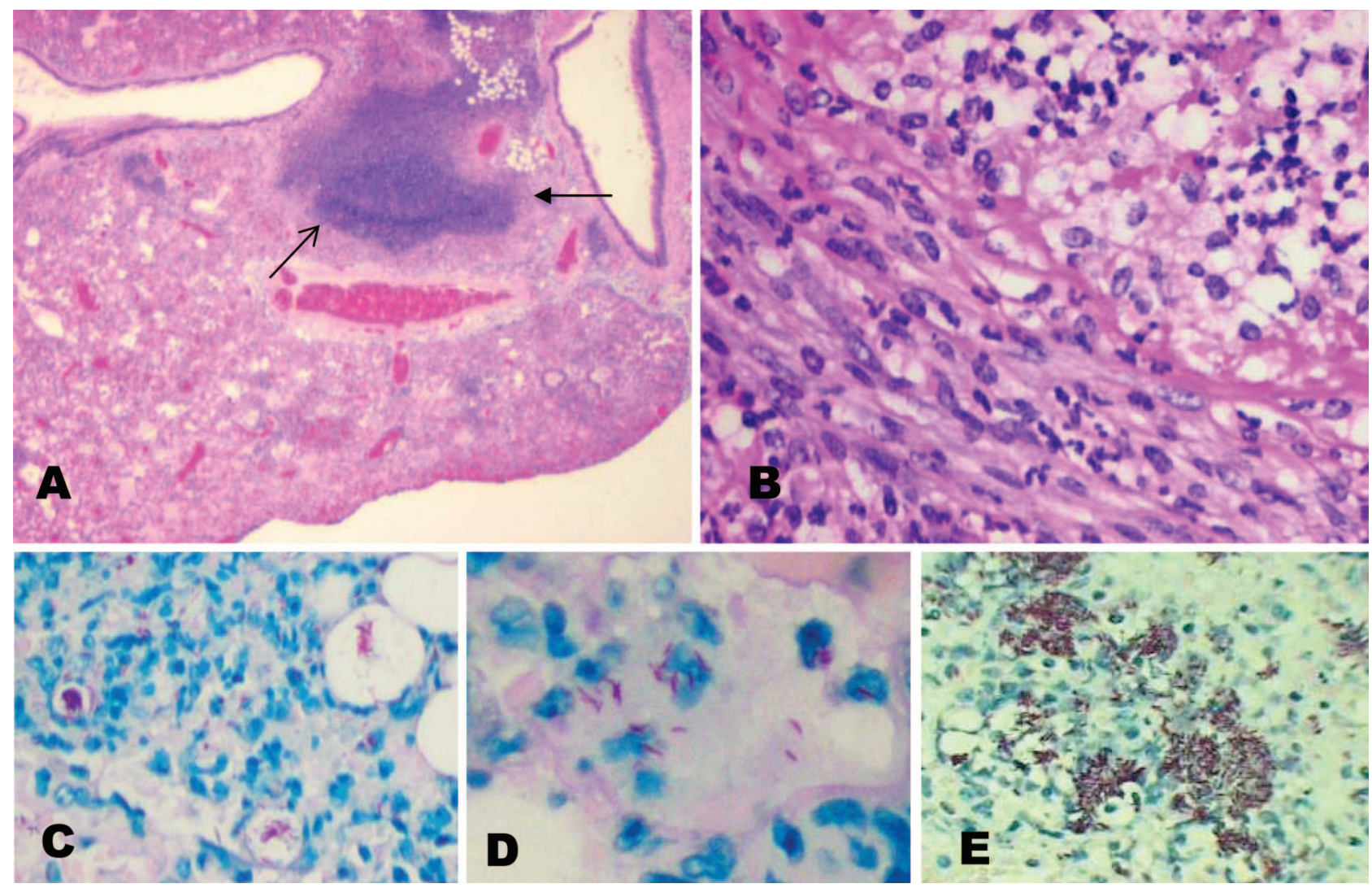

Figure 7. Distribution of caseating granulomas and exudative reactions in lung. Sections of mouse lung 3 days after injection of $10^{9} \mathrm{MTB}$ into the lung. The animals had been infected intraperitoneally with $10^{4}$ MTB 4 months earlier. A: Photomicrograph showing solitary caseating granuloma (open arrow) in an area of lung with fat cells (closed arrow) near the hilus at 3 days. The remainder of the lung has an exudative reaction (H\&E). B: Detail of caseating granuloma (near open arrow on A) showing epithelioid cells surrounding lipid-rich necrotic material (H\&E). C: Detail (near closed arrow on A) showing MTB (AFB) in lipid of fat cells at the periphery of the lesion (AFB). D: MTB in the lung at day 3. The large majority of organisms have been cleared from the lung. The remaining AFB are confined to alveolar macrophages (AFB stain). E: MTB in the lung at 1 day. Many AFB are located in alveolar walls, in alveolar macrophages, and associated with dead cells (AFB stain). Original magnifications: $\times 20(\mathbf{A}) ; \times 400(\mathbf{B}, \mathbf{C}, \mathbf{E}) ; \times 1000(\mathbf{D})$

phils. AFB dispersed in alveoli at 1 hour were greatly reduced by 24 hours and the large clumps had lost most of their acid-fast staining. The inflammatory reaction was a characteristic allergic pneumonitis consisting of interstitial and alveolar macrophages intermixed with acute inflammatory cells and pyknotic nuclei of dead cells in proteinacious edema peaked at 3 days after most of the organisms had disappeared (Figure 7D). These lesions resolved completely by 3 weeks. There was no evidence of persistent infection at the site of injection where vast numbers of organisms had been deposited.

Caseating granulomas developed in the lungs of these mice in association with adipose tissue, not at the site of injection (Figure 7A). They developed rapidly and were typically solitary lesions even though the initial infection had been widespread. On day 3 after injection, they consisted of epithelioid macrophages surrounding masses of necrotic tissue that appeared dark because of nuclear debris (Figure 7B). AFB were present in fat cells at the periphery of the lesions and in lipid drops within the lesions (Figure 7C). Similar caseating granulomas were also found in mediastinal fatty tissue (Figure 8B). They presumably resulted from organisms deposited in the pleural cavity. After 3 weeks, the lesions grossly had the white appearance of caseation necrosis. Microscopi- cally, nuclear debris had been cleared from the centers of the granulomas leaving characteristic pink amorphous material (Figure 8C). The necrotic centers were surrounded first by foamy macrophages, then epithelioid cells, and finally lymphoid cells (Figure 8 C). Large numbers of AFB persisted in the necrotic material within caseating granulomas after all visible organisms had been cleared from other parts of the lung. Similar injection of a lower dose $\left(10^{7}\right)$ of organisms produced only a transient exudative reaction and no caseating granulomas (data not shown).

Experiments were conducted to determine whether the inability to induce caseating granulomas in the lung away from adipose tissue was due to insufficient lipid. Sensitized mice were injected in the lung with MTB plus TDM in an oil-in-water emulsion. These animals developed caseating granulomas in the lung parenchyma at the site of injection (Figure 9). These lesions were not associated with fat cells, but incorporated the oil drops in a pattern similar to that observed with lipid of adipose cells. At early time points, AFB were prominently seen within oil droplets within these granulomas. Some of these granulomas developed softening of the necrotic centers in a manner reminiscent of the process that leads to cavities in man. ${ }^{24,25,41}$ Injection of the oil emulsion alone induced 

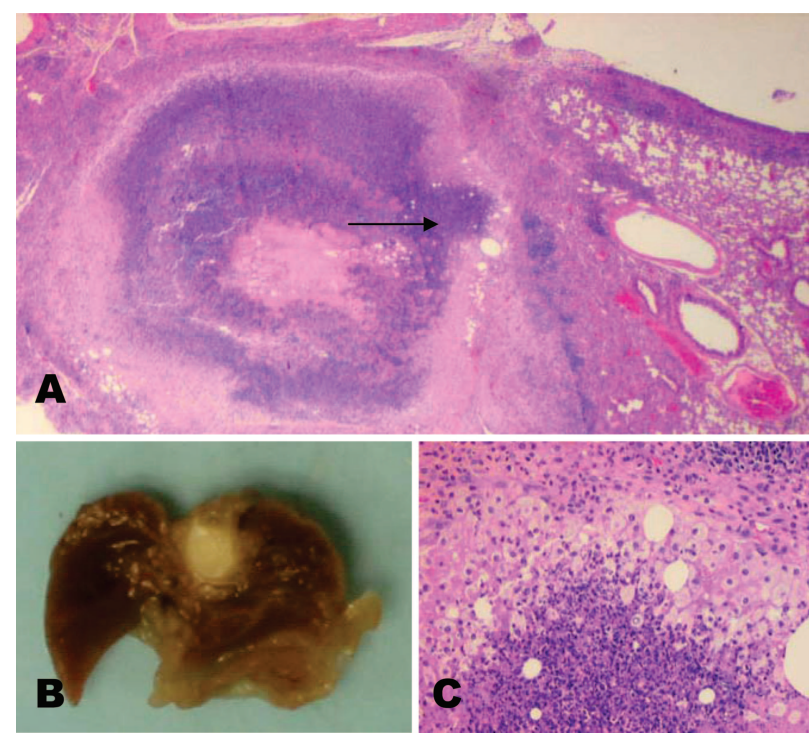

Figure 8. Caseating granuloma in a mouse lung. The animal was treated as described in Figure 7 and examined on day 24. A: Photomicrograph of the same lesion showing a caseating granuloma adjacent to the esophagus and invading the lung (H\&E). B: Gross photograph of fixed mouse lungs showing solitary white lesion in a central location where adipose tissue is found. $\mathbf{C}$ : Detail of edge lesion (near arrow on $\mathbf{A}$ ) showing necrotic tissue (bottom) surrounded by foamy macrophages, remnants of fat cells, epithelioid macrophages, and finally lymphoid cells (top) (H\&E). Original magnifications: $\times 20(\mathbf{A}) ; \times 200(\mathbf{C})$.

only mild foreign body-type granulomas as reported previously. ${ }^{14,16,42}$

\section{Effect of Removal of Surface Lipids from MTB}

Studies were conducted with delipidated MTB. Organisms were extracted with wet petroleum ether to remove lipids, primarily TDM, loosely deposited on the surface without affecting viability. ${ }^{43}$ Others have reported that such organisms induce acute rather than granulomatous inflammation and fail to survive in mac-

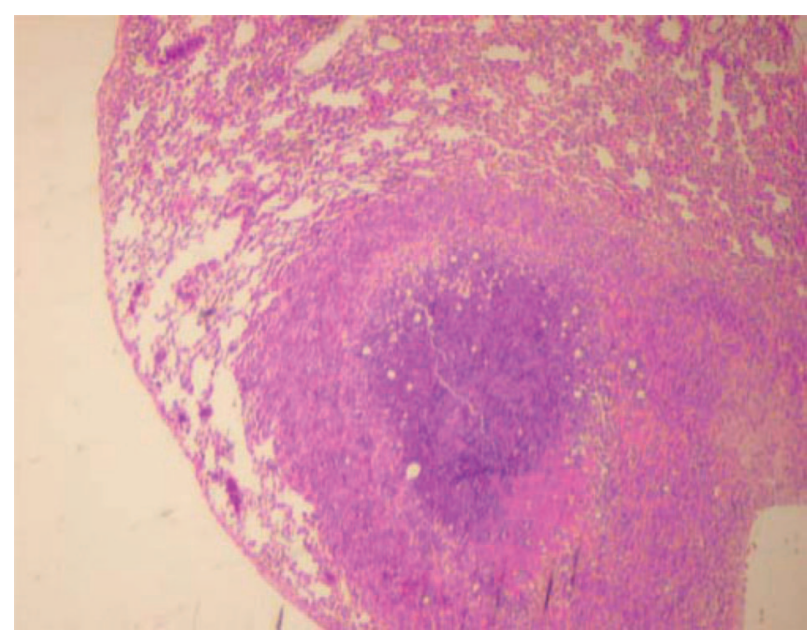

Figure 9. Caseating granuloma induced by TDM with MTB in oil. The animal was injected in the lung with $10^{7}$ MTB plus $100 \mu \mathrm{g}$ of TDM in a $2 \%$ oil-in-water emulsion 30 days after immunization with $10^{4}$ MTB intraperitoneally and examined on day 14 . The section shows a caseating granuloma around lipid droplets of the oil emulsion (H\&E). Original magnification, $\times 40$.

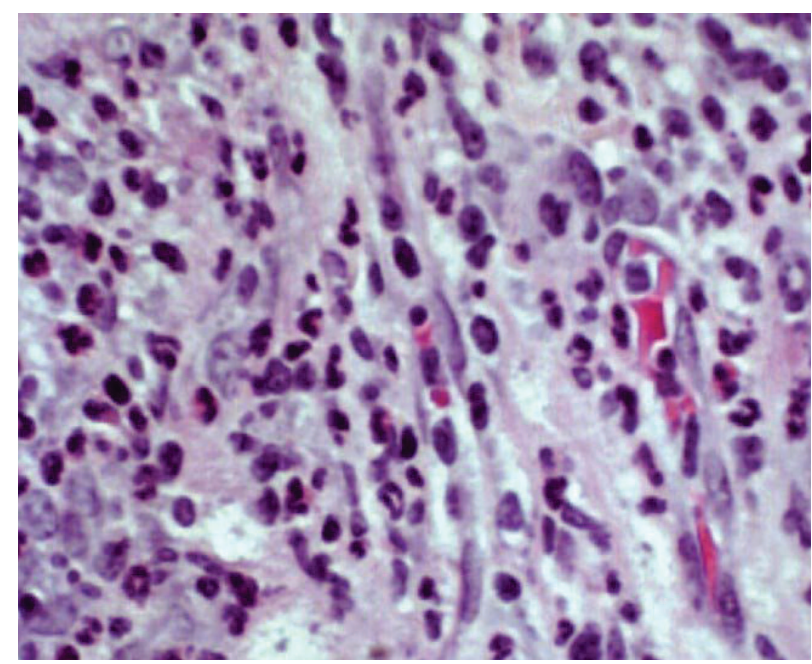

Figure 10. Inflammatory reaction to delipidated MTB. Section of mediastinal tissue 6 days after injection of $10^{9}$ delipidated MTB into the lung. The acute inflammatory reaction in the lung had primarily subsided leaving a resolving acute inflammatory reaction. No caseating or noncaseating granulomas were observed even when the organisms had been injected into adipose tissue (H\&E). Original magnification, $\times 400$.

rophages. ${ }^{10,11}$ Sensitized mice were injected directly in to the lung with $10^{9}$ delipidated MTB or an equal number of native MTB. The native MTB produced lesions as described above. The delipidated MTB induced a very different reaction. Initially, large numbers of AFB were observed at the site of injection. By 24 hours, they had induced an intense acute inflammatory response composed primarily of neutrophils with only a few macrophages. Most AFB had disappeared, presumably as a result of being killed, by 24 hours. The remaining MTB were in large clumps surrounded by viable neutrophils. This contrasted with the histopathological changes induced by MTB in which there was a more even mixture of neutrophils and macrophages and much debris of dead inflammatory cells. Furthermore, no organisms were observed distributed singly within alveoli or within alveolar macrophages as was commonly seen with MTB at early time points (Figure 7D). By day 6, all of the organisms had been cleared from the lungs and surrounding tissues leaving only resolving acute inflammation (Figure 10). No caseating or noncaseating granulomas were observed even when the organisms had been injected into adipose tissue.

\section{Discussion}

Caseating granulomas are the characteristic lesion of active tuberculosis in humans. The term caseation is commonly used to embrace all forms of gross necrosis associated with tuberculosis. ${ }^{44}$ Although there are several variations, caseation generally refers to a process of coagulation necrosis in which the cells, primarily macrophages, lose their outline, become irregular, no longer take stains and are finally converted into a homogeneous, structureless substance composed primarily of lipids. ${ }^{26}$ 
The necrotic material forms a cheesy mass that may undergo softening, fibrous encapsulation, and calcification.

Caseating granulomas benefit both the host and parasite in tuberculosis. They benefit the host by sequestering organisms in an environment where most eventually die. ${ }^{38,41}$ They are essential for survival of the organism because they facilitate transmission to new hosts. MTB is an obligate human parasite. It can infect many species, but is transmitted only by humans and has no environmental reservoir. Consequently, its survival depends on transmission from person to person. ${ }^{45}$ Most transmission of infection occurs via caseating granulomas in the lung that have eroded into bronchi to form cavities in which MTB multiply in vast numbers to be coughed into the environment. ${ }^{24,40,45,46}$ The importance of improved understanding of caseating granulomas is such that the National Institutes of Health recently placed it first on a list of priorities for future studies of the genetics of tuberculosis. ${ }^{47}$

Guinea pigs, rabbits, dogs, and monkeys infected with low doses of MTB produce caseating granulomas. Mice with tuberculosis characteristically produce granulomas, but fail to develop necrosis resembling caseation. ${ }^{39} \mathrm{Ca}-$ seating granulomas have been reported in mice infected with a highly virulent strain of $M$. avium and lesions with some characteristics of caseation have been reported in certain strains of mice and during advanced tuberculosis. ${ }^{22,29,48}$ Nevertheless, the paucity of murine models of caseating granulomas has primarily precluded the application of the tools of modern biology to their investigation.

The key departure of this project was the observation that TDM injected intraperitoneally into mice sensitized by low-dose infection with MTB induced caseating granulomas. These lesions were distinctly different from the activated foreign body-type granulomas induced by TDM injected similarly into normal mice. ${ }^{16,36,49}$ They had the appearance of hypersensitivity granulomas and developed preferentially in adipose tissue of the mesentery and omentum. It appeared as if lipid from dead fat cells was being incorporated into caseous necrosis by the action of macrophages. The lesions persisted for several months and then gradually healed. Large multinucleated macrophages resembling Langhans giant cells were observed during the healing phase at 62 days. Such cells are characteristic of human tuberculosis, but have only rarely been reported in mice. ${ }^{50}$

It has long been assumed that caseating granulomas of tuberculosis result from an immune reaction to mycobacterial proteins. ${ }^{38}$ However, infection also produces immunity (hypersensitivity) to branched chain fatty acids. ${ }^{5,51} \mathrm{~T}$ cells specific for TDM or mycolic acid have been reported by multiple investigators. ${ }^{4,35,52,53}$ The present studies suggest that an immune response against TDM may be an important component of the pathogenesis of caseating granulomas.

Having established that TDM could induce caseating granulomas in sensitized mice, studies were undertaken to determine whether MTB containing abundant TDM could induce such lesions. The caseating granulomas induced by MTB in sensitized mice had both similarities and significant differences from those induced by TDM alone. Mice injected with the highest dose consistently developed caseating granulomas preferentially in fat tissue. These lesions also had the appearance of hypersensitivity granulomas in that caseous necrotic cores were surrounded by epithelioid cells mixed with lymphocytes and other inflammatory cells. The necrotic centers were larger and more completely homogenized than those of TDM-induced lesions suggesting that components of MTB in addition to TDM were important. In addition, they contained very large numbers of AFB. The caseating granulomas produced by injection of MTB also had morphological characteristics of delayed type hypersensitivity. ${ }^{24,37}$ Delayed type hypersensitivity reactions such as rejection of skin grafts or tuberculin skin tests are characterized by vasculitis and fibrin surrounding an area of tissue producing infarction. Vasculitis and infarcted tissue were features of the lesions induced by MTB, but not by TDM alone.

Nonimmune caseating granulomas were produced during primary infection of normal mice by injection of a high dose of MTB. Lesions formed within 2 weeks in adipose tissue and contained vast numbers of AFB within necrotic centers. AFB were consistently observed in fat cells at the periphery of these lesions. These lesions differed from those in sensitized animals in that their walls consisted of epithelioid macrophages with almost no lymphocytes suggesting that they were nonimmune granulomas. They differed from the nonimmune granulomas induced by TDM in normal animals in that they were more compact, contained more epithelioid cells, and had necrotic centers. AFB in the peritoneal cavity were exclusively located in these lesions. A few scattered organisms were present in the liver, spleen, and lung, but had not induced significant pathology.

MTB were regularly observed in fat cells or oil drops in association with development of caseating granulomas. Although this was unexpected, preferential localization of caseating granulomas in adipose tissue is characteristic of human tuberculosis of the mesentery, skin, pancreas, breast, and bone marrow. ${ }^{27,28,54-57}$ Developing caseation in our studies appeared to be anatomically associated with ingestion of fat by macrophages and transformation into foamy macrophages that died to form caseation. Review of the literature revealed that many components of this process have been reported previously. Caseation necrosis is composed primarily of host lipid some of which is derived from foamy macrophages with altered lipid metabolism. ${ }^{26,30,58-60}$ Invasion of fat cells by MTB has been reported in animals injected with large doses of MTB and AFB have been observed in lipid droplets in sections of human tuberculosis. ${ }^{61}$

Because most clinical tuberculosis in immunocompetent humans, as in mice, is pulmonary, studies were undertaken to determine whether caseating granulomas could be induced in the lung. ${ }^{22}$ It was known that intrapulmonary injections of virulent MTB or mycobacterial lipids can produce caseating granulomas and cavities in sensitized guinea pigs and rabbits. ${ }^{62-65}$ Modern texts on the histogenesis of pulmonary tuberculosis are based primarily of studies in rabbits and guinea pigs and have diverged significantly from older descriptions of the hu- 
man disease. ${ }^{46}$ In the prechemotherapy era, investigators reported that caseating granulomas in the lungs of people develop rapidly from necrosis of pneumonic lesions in which very large numbers of MTB are present in the alveoli of sensitized hosts. ${ }^{23-25,30}$ Consequently, we hypothesized that injection of large numbers of MTB into the lung of a sensitized mouse would produce a pneumonic process leading to caseating granulomas. We found that such injections did produce a pneumonic process and caseating granulomas, but the two were not related. This led to new insights.

We were concerned that the high dose of virulent organisms would overwhelm the defenses of the animals and produce rapid death from uncontrolled infection and/or toxicity. However, we found, as have others, that animals tolerated massive injections of MTB surprisingly well killing most of the organisms within a few days with a transient acute inflammatory process. ${ }^{66-68}$ This was consistent with reports that neutrophils can kill MTB during early stages of infection. ${ }^{69}$ In one study, $100 \%$ of MTB were killed during overnight cultivation with neutrophils at a multiplicity of infection of 10:1. ${ }^{70}$ In another study, stimulation of a neutrophil exudate in the lung before aerosol infection with MTB resulted in a $99.9 \%$ reduction in surviving organisms at 10 days. ${ }^{70}$ Neutrophils had no effect on established infections. ${ }^{69,70}$

AFB and inflammation persisted in the lungs of mice in this experiment only in caseating granulomas that formed in adipose tissue. These lesions were identified as early as 3 days after injection of MTB and were formed only in areas of lung near the hilus that contained fat. In all of our studies, caseating granulomas were observed in areas of the lung devoid of fat only if MTB and/or TDM had been injected in oil. In these mice, the lesions centered on oil droplets in a pattern similar to that of fat cells. This suggests that multiple lipids, not just fat, can protect MTB in a hostile environment and support the production of caseating granulomas.

The production of caseating granulomas in adipose tissue may be a valuable model of some extrapulmonary, but not of pulmonary, tuberculosis because lesions typically arise in regions of the lung that contain little fat. ${ }^{27,28}$ Nevertheless, there may be common principles. It has long been known that pulmonary caseous necrotic material in humans is composed primarily of host lipid. ${ }^{26,58}$ In addition, North and Jung ${ }^{22}$ have noted that of all of the commonly used experimental species, only the mouse develops a chronic infection that, like most human tuberculosis, is restricted to the lung. In mice with slowly progressive tuberculosis, large amounts of lipid, especially cholesterol, becomes concentrated in alveoli. ${ }^{31,71}$ Early in the disease, this lipid resides in foamy alveolar macrophages. During later stages, free lipid droplets accumulate within alveolar spaces. ${ }^{72}$ It seems likely that pulmonary surfactant contributes to this process because mycobacterial lipids are known to modulate its function and it influences the interaction of mycobacteria with alveolar macrophages. ${ }^{73-76}$ In the present studies, we observed that most AFB in the lungs of animals with advanced pulmonary tuberculosis were within or closely associated with lipid drops in developing necrotic foci.
Most literature on the histogenesis of pulmonary tuberculosis follows the rabbit model that caseating granulomas develop from progressive expansion of smaller granulomas. ${ }^{46,68}$ However, caseation necrosis in adult human pulmonary tuberculosis may develop via a different process as a tuberculous pneumonia with infection restricted to foamy alveolar macrophages. ${ }^{23-25}$ Progressive accumulation of cholesterol-rich lipid in alveolar macrophages leading to caseating granulomas in man has been reported. ${ }^{30,58}$ These lesions may rapidly undergo necrosis to produce caseating granulomas and cavities. To the extent that this is an accurate description of the histogenesis of human disease, slowly progressive tuberculosis in mice may be a better model of human pulmonary tuberculosis than is generally recognized. It shares several common features with developing human secondary pulmonary tuberculosis. Early infection in is confined to alveolar macrophages that progressively accumulate mycobacterial products and lipid for approximately a year until necrosis abruptly occurs. ${ }^{23,29-31}$ In both species, the necrosis involves lipid-rich material with macrophages and neutrophils. Mice die with $80 \%$ lung involvement whereas humans usually survive with less than $25 \%$ of their lung tissue involved. $22,26,29,40$

The role of TDM in the pathogenesis of tuberculosis has been controversial for decades. ${ }^{12,20}$ The controversy centers on the observation that TDM injected in oil is highly toxic for some strains of mice $\left(\mathrm{LD}_{50} \sim 30 \mu \mathrm{g}\right)$ whereas the same material injected in saline is nontoxic $\left(\mathrm{LD}_{50} \gg 50 \mathrm{mg}\right)$. The requirement for an oily vehicle was considered "unphysiologic." 77,78 It may now be possible to resolve this controversy. TDM is present in large quantity free on the surface of virulent MTB where it can be extracted by oily substances. ${ }^{1,3,11,79}$ Such extraction reduces virulence and the capacity to induce caseating granulomas. ${ }^{10,43,80}$ Furthermore, oil activates the toxicity of TDM by providing a suitable surface to support formation of a crystalline monolayer. ${ }^{13,14,18,19}$ The toxicity of TDM is a function of the surface area and particle size of the TDM monolayer and is not otherwise related to dose. ${ }^{13,14,81}$ The demonstration that MTB can stimulate the accumulation of lipid droplets and enter them in vivo as it does oil drops in vitro suggests that the activation of the toxicity of TDM at oil-water interfaces is physiological. We propose that if MTB enters a lipid droplet, TDM comes off the organism, forms a surface monolayer, and is thereby transformed from a nontoxic protector of the organism to the driver of caseating granulomas due to a combination of its toxicity and a cell-mediated immune response against TDM. The stability of the toxic monolayer may contribute to chronicity of lesions and explain why macrophages cannot survive within them.

\section{References}

1. Brennan PJ, Nikaido $\mathrm{H}$ : The envelope of mycobacteria. Ann Rev Biochem 1995, 64:29-63

2. Yano I: The 72nd Annual Meeting Education Lecture. Cord factor Kekkaku 1998, 73:37-42

3. Hunter RL, Venkatprasad N, Olsen M: The role of trehalose dimyco- 
late (cord factor) in morphology of virulent $\mathrm{M}$. tuberculosis in vitro. Tuberculosis (Edinb). 2005 Dec 9; [Epub ahead of print]

4. Ryll R, Kumazawa Y, Yano I: Immunological properties of trehalose dimycolate (cord factor) and other mycolic acid-containing glycolipids-a review. Microbiol Immunol 2001, 45:801-811

5. Youmans GP: Mycobacterial lipids: chemistry and biologic activities. Tuberculosis. Edited by Youmans GP. Philadelphia, W.B. Saunders Co., 1979, pp 63-193

6. Perez RL, Roman J, Roser S, Little C, Olsen M, Indrigo J, Hunter RL, Actor JK: Cytokine message and protein expression during lung granuloma formation and resolution induced by the mycobacterial cord factor trehalose-6,6'-dimycolate. J Interferon Cytokine Res 2000 20:795-804

7. Bekierkunst A, Yarkoni E: Granulomatous hypersensitivity to trehalose-6,6'-dimycolate (cord factor) in mice infected with BCG. Infect Immun 1973, 7:631-638

8. Sugawara I, Udagawa T, Hua SC, Reza-Gholizadeh M, Otomo K, Saito Y, Yamada H: Pulmonary granulomas of guinea pigs induced by inhalation exposure of heat-treated BCG Pasteur, purified trehalose dimycolate and methyl ketomycolate. J Med Microbiol 2002, $51: 131-137$

9. Yamagami H, Matsumoto T, Fujiwara N, Arakawa T, Kaneda K, Yano I, Kobayashi K: Trehalose 6,6'-dimycolate (cord factor) of Mycobacterium tuberculosis induces foreign-body- and hypersensitivity-type granulomas in mice. Infect Immun 2001, 69:810-815

10. Silva CL, Ekizlerian SM, Fazioli RA: Role of cord factor in the modulation of infection caused by mycobacteria. Am J Pathol 1985, 118:238-247

11. Indrigo J, Hunter Jr RL, Actor JK: Cord factor trehalose 6,6'-dimycolate (TDM) mediates trafficking events during mycobacterial infection of murine macrophages. Microbiology 2003, 149:2049-2059

12. Youmans GP: Biologic activities of mycobacterial cells and cell components. Tuberculosis. Edited by Youmans GP. Philadelphia, W.B. Saunders, 1979, pp 46-62

13. Retzinger GS, Meredith SC, Takayama K, Hunter RL, Kezdy FJ: The role of surface in the biological activities of trehalose 6,6'-dimycolate. Surface properties and development of a model system. J Biol Chem 1981, 256:8208-8216

14. Retzinger GS, Meredith SC, Hunter RL, Takayama K, Kezdy FJ: Identification of the physiologically active state of the mycobacterial glycolipid trehalose $6,6^{\prime}$-dimycolate and the role of fibrinogen in the biologic activities of trehalose 6,6'-dimycolate monolayers. J Immunol 1982, 129:735-744

15. Bloch $\mathrm{H}$, Noll H: Studies on the virulence of tubercle bacilli. The effect of cord factor on murine tuberculosis. Br J Exp Pathol 1955, 36:8-17

16. Behling CA, Perez RL, Kidd MR, Staton GJ, Hunter RL: Induction of pulmonary granulomas, macrophage procoagulant activity, and tumor necrosis factor-alpha by trehalose glycolipids. Ann Clin Lab Sci 1993, 23:256-266

17. Syed SS, Hunter RL: Studies on the toxic effects of quartz and a mycobacterial glycolipid, trehalose 6,6'-dimycolate. Ann Clin Lab Sci 1997, 27:375-383

18. Behling CA, Bennett B, Takayama K, Hunter RL: Development of a trehalose $6,6^{\prime}$-dimycolate model which explains cord formation by Mycobacterium tuberculosis. Infect Immun 1993, 61:2296-2303

19. Schabbing RW, Garcia A, Hunter RL: Characterization of the trehalose 6,6'-dimycolate surface monolayer by scanning tunneling $\mathrm{mi}$ croscopy. Infect Immun 1994, 62:754-756

20. Goren M: Cord factor revisited: a tribute to the late Hubert Bloch. Tubercle 1975, 56:65-71

21. Dannenberg Jr AM, Collins FM: Progressive pulmonary tuberculosis is not due to increasing numbers of viable bacilli in rabbits, mice and guinea pigs, but is due to a continuous host response to mycobacterial products. Tuberculosis (Edinb) 2001, 81:229-242

22. North RJ, Jung YJ: Immunity to tuberculosis. Annu Rev Immunol 2004, 22:599-623

23. Pagel W, Simmonds F, MacDonald N, Nassau E: The morbid anatomy and histology of tuberculosis, an introduction in simple terms. Pulmonary Tuberculosis, Bacteriology, Pathology, Management, Epidemiology and Prevention. London, Oxford University Press, 1964, pp $36-63$

24. Florey H: Tuberculosis. General pathology based on lectures delivered at the Sir William Dunn School of Pathology, University of Oxford. Philiadelphia, W.B Saunders, 1958, pp 829-870
25. Levine ER: Classification of reinfection pulmonary tuberculosis. The Fundamentals of Pulmonary Tuberculosis and its Complications. Edited by Hayes E. Springfield, Charles C. Thomas, 1949, pp 97-113

26. Gunn FD: Tuberculosis. Pathology, ed 4. Edited by Anderson WAD. St. Louis, C.V. Mosby Company, 1961, pp 243-263

27. Uygur-Bayramicli O, Dabak G, Dabak R: A clinical dilemma: abdominal tuberculosis. World J Gastroenterol 2003, 9:1098-1101

28. Tandon HD, Prakash A: Pathology of intestinal tuberculosis and its distinction from Crohn's disease. Gut 1972, 13:260-269

29. Mustafa T, Phyu S, Nilsen R, Jonsson R, Bjune G: A mouse model for slowly progressive primary tuberculosis. Scand J Immunol 1999, 50:127-136

30. Pagel W, Pagel W: Zur Histochemie der Lungentuberkulose, mit besonderer Berucksichtung der Fettsubstanzen und Lipoide. (Fat and lipoid content to tuberculous tissue. Histochemical investigation.). Virchows Arch Pathol Anat 1925, 256:629-640

31. Cardona PJ, Gordillo S, Diaz J, Tapia G, Amat I, Pallares A, Vilaplana $C$, Ariza A, Ausina V: Widespread bronchogenic dissemination makes DBA/2 mice more susceptible than C57BL/6 mice to experimental aerosol infection with Mycobacterium tuberculosis. Infect Immun 2003, 71:5845-5854

32. Bloch $\mathrm{H}$ : Studies on the virulence of tubercle bacilli: isolation and biological properties of a constituent of virulent organisms. J Exp Med 1950, 91:197-219

33. Pierce C: Infection of mice with mammalian tubercle bacilli grown in Tween-albumin medium. J Exp Med 1947, 86:159-174

34. Watson VE, Hill LL, Owen-Schaub LB, Davis DW, McConkey DJ, Jagannath C, Hunter Jr RL, Actor JK: Apoptosis in Mycobacterium tuberculosis infection in mice exhibiting varied immunopathology. J Pathol 2000, 190:211-220

35. Guidry TV, Olsen M, Kil KS, Hunter Jr RL, Geng YJ, Actor JK: Failure of CD1D-/- mice to elicit hypersensitive granulomas to mycobacterial cord factor trehalose 6,6'-dimycolate. J Interferon Cytokine Res 2004, 24:362-371

36. Bekierkunst A, Levij IS, Yarkoni E, Vilkas E, Adam A, Lederer E: Granuloma formation induced in mice by chemically defined mycobacterial fractions. J Bacteriol 1969, 100:95-102

37. Dvorak HF, Galli SJ, Dvorak AM: Cellular and vascular manifestations of cell-mediated immunity. Hum Pathol 1986, 17:122-137

38. Dannenberg Jr AM: Roles of cytotoxic delayed-type hypersensitivity and macrophage-activating cell-mediated immunity in the pathogenesis of tuberculosis. Immunobiology 1994, 191:461-473

39. Lefford ML: Diseases in mice and rats. The Mycobacteria: A Sourcebook. Edited by Wayne G.K.AL. New York, Marcel Dekker, 1984, pp 947-977

40. Garay S: Pulmonary tuberculosis. Tuberculosis. Edited by Garay W.R.S. Boston, Little Brown \& Co, 1996, pp 373-412

41. Yoder M, Lamichhane G, Bishai W: Cavitary pulmonary tuberculosis: the Holy Grail of disease transmission. Curr Sci 2004, 86:74-81

42. Bekierkunst $\mathrm{A}$ : Acute granulomatous response produced in mice by trehalose-6,6-dimycolate. J Bacteriol 1968, 96:958-961

43. Indrigo J, Hunter Jr RL, Actor JK: Influence of trehalose 6,6'-dimycolate (TDM) during mycobacterial infection of bone marrow macrophages. Microbiology 2002, 148:1991-1998

44. Ridley DS, Ridley MJ: Rationale for the histological spectrum of tuberculosis. A basis for classification. Pathology 1987, 19:186-192

45. Grosset J: Mycobacterium tuberculosis in the extracellular compartment: an underestimated adversary. Antimicrob Agents Chemother 2003, 47:833-836

46. Dannenburg A: Pathophysiology: basic aspects. Tuberculosis and nontuberculous mycobacterial infections, ed 4 . Edited by Schlossberg D. Philadelphia, W.B. Saunders, 1999, pp 26-27

47. Smith I, Nathan C, Peavy HH, NHLBI Working Group: Progress and new directions in genetics of tuberculosis. Am J Respir Crit Care Med 2005, 172:1491-1496

48. Ehlers S, Benini J, Held HD, Roeck C, Alber G, Uhlig S: Alphabeta T cell receptor-positive cells and interferon-gamma, but not inducible nitric oxide synthase, are critical for granuloma necrosis in a mouse model of mycobacteria-induced pulmonary immunopathology. J Exp Med 2001, 194:1847-1859

49. Perez RL, Roman J, Staton GJ, Hunter RL: Extravascular coagulation and fibrinolysis in murine lung inflammation induced by the mycobacterial cord factor trehalose-6,6'-dimycolate. Am J Respir Crit Care Med 1994, 149:510-518 
50. Sugawara I, Yamada H, Kazumi Y, Doi N, Otomo K, Aoki T, Mizuno S, Udagawa T, Tagawa Y, Iwakura Y: Induction of granulomas in interferon-gamma gene-disrupted mice by avirulent but not by virulent strains of Mycobacterium tuberculosis. J Med Microbiol 1998 , 47:871-877

51. Catel W, Schmidt W: Klinische und experimetelle untersuchunge uber das wessen der lokalen tuberkulin empfindlichkeit. Deut Med Wochenschr 1950, 75:1140

52. Moody DB, Guy MR, Grant E, Cheng TY, Brenner MB, Besra GS, Porcelli SA: CD1b-mediated T cell recognition of a glycolipid antigen generated from mycobacterial lipid and host carbohydrate during infection. J Exp Med 2000, 192:965-976

53. Ulrichs T, Moody DB, Grant E, Kaufmann SH, Porcelli SA: T-cell responses to CD1-presented lipid antigens in humans with Mycobacterium tuberculosis infection. Infect Immun 2003, 71:3076-3087

54. Cohen C: Tuberculous mastitis. A review of 34 cases. S Afr Med J 1977, 52:12-14

55. Dent DM, Webber BL: Tuberculosis of the breast. S Afr Med J 1977, $51: 611-614$

56. Jordaan HF, Schneider JW, Abdulla EA: Nodular tuberculid: a report of four patients. Pediatr Dermatol 2000, 17:183-188

57. Kumar R, Kapoor D, Singh J, Kumar N: Isolated tuberculosis of the pancreas: a report of two cases and review of the literature. Trop Gastroenterol 2003, 24:76-78

58. Medlar E: A study of the process of caseation in tuberculosis. Am J Pathol 1926, 2:275-290

59. Jayasundar R, Singh VP, Raghunathan P, Jain K, Banerji AK: Inflammatory granulomas: evaluation with proton MRS. NMR Biomed 1999 12:139-144

60. Birkun AA: Disorders of fat metabolism in the lungs in tuberculosis Pathomorphological and histochemical characteristics. Arkh Patol 1963, 25:23-32

61. Mauss H, Levy FM: Involvement of adipose tissue in experimenta tuberculosis of the mouse. Pathol Microbiol (Basel) 1972, 38:333-345

62. Hamamoto Y, Kobara Y, Kojima A, Kumazawa Y, Yasuhira K: Experimental production of pulmonary granulomas. I. Immune granulomas induced by chemically modified cell walls and their constituents. $\mathrm{Br} J$ Exp Pathol 1981, 62:259-269

63. Yamamura Y, Maeda H, Ogawa Y, Hashimoto T: Experimental pulmonary cavity formation by mycobacterial components and synthetic adjuvants. Microbiol Immunol 1986, 30:1175-1187

64. Maeda H, Yamamura Y, Ogawa Y, Maeda J: Mycobacterial antigens relating to experimental pulmonary cavity formation. Am Rev Respir Dis $1977,115: 617-623$

65. Khomenko AG, Golyshevskaia VI: Model of destructive tuberculosis in guinea pigs. Biull Eksp Biol Med 1981, 92:627-629

66. Bloch $\mathrm{H}$ : Bacterial components concerned in the early phase of infection. CIBA Foundation Symposium on Experimental Tuberculosis. Edited by G.E.W. Wolstenholme, M.P. Cameron, C. O'Conner. Boston, Little Brown \& Co., 1955, pp 131-137
67. Lurie M: The correlation between the histological changes and the fate of living tubercle bacilli in the organs of tuberculous rabbits. $J$ Exp Med 1932, 55:31-54

68. Lurie M, Abramson S, Heppleston A: On the response of genetically resistant and susceptible rabbits to the quantitative inhalation of human type tubercle bacilli and the nature of resistance to tuberculosis. J Exp Med 1952, 95:119-135

69. Pedrosa J, Saunders BM, Appelberg R, Orme IM, Silva MT, Cooper AM: Neutrophils play a protective nonphagocytic role in systemic Mycobacterium tuberculosis infection of mice. Infect Immun 2000, 68:577-583

70. Sugawara I, Udagawa T, Yamada H: Rat neutrophils prevent the development of tuberculosis. Infect Immun 2004, 72:1804-1806

71. Dunn PL, North RJ: Persistent infection with virulent but not avirulent Mycobacterium tuberculosis in the lungs of mice causes progressive pathology. J Med Microbiol 1996, 45:103-109

72. Korf J, Stoltz A, Verschoor J, De Baetselier P, Grooten J: The Mycobacterium tuberculosis cell wall component mycolic acid elicits pathogen-associated host innate immune responses. Eur J Immunol 2005, 35:890-900

73. Chimote G, Banerjee R: Lung surfactant dysfunction in tuberculosis: effect of mycobacterial tubercular lipids on dipalmitoylphosphatidylcholine surface activity. Colloids Surf B Biointerfaces 2005, 45:215-223

74. Riviere M, Moisand A, Lopez A, Puzo G: Highly ordered supramolecular organization of the mycobacterial lipoarabinomannans in solution. Evidence of a relationship between supra-molecular organization and biological activity. J Mol Biol 2004, 344:907-918

75. Ferguson JS, Voelker DR, Ufnar JA, Dawson AJ, Schlesinger LS Surfactant protein D inhibition of human macrophage uptake of Mycobacterium tuberculosis is independent of bacterial agglutination. J Immunol 2002, 168:1309-1314

76. Pasula R, Wright JR, Kachel DL, Martin II WJ: Surfactant protein A suppresses reactive nitrogen intermediates by alveolar macrophages in response to Mycobacterium tuberculosis. J Clin Invest 1999, 103:483-490

77. Daffe M, Draper P: The envelope layers of mycobacteria with reference to their pathogenicity. Adv Microbial Physiol 1998, 39:131-203

78. Goren MB, Brennan PJ: Mycobacterial lipids: chemistry and biologic activities. Tuberculosis. Edited by Youmans GP. Philadelphia, W.B. Saunders, 1979, pp 63-193

79. Rao V, Fujiwara N, Porcelli SA, Glickman MS: Mycobacterium tuberculosis controls host innate immune activation through cyclopropane modification of a glycolipid effector molecule. J Exp Med 2005 201:535-543

80. Bloch H: Virulence of mycobacteria. Adv Tuberc Res 1955, 6:49-61

81. Geisel RE, Sakamoto K, Russell DG, Rhoades ER: In vivo activity of released cell wall lipids of Mycobacterium bovis Bacillus CalmetteGuerin is due principally to trehalose mycolates. J Immunol 2005, 174:5007-5015 